\title{
Evaluation of Informant Consensus Factor of Medicinal Plants Used in Shamozai Valley SWAT, KPK, Pakistan
}

\author{
Shariat Ullah ${ }^{1 *}$, Noor Muhammad ${ }^{2}$ \\ ${ }^{1}$ Department of Botany, University of Malakand, Chakdara, Pakistan \\ ${ }^{2}$ Department of Botany, Hazara University, KPK, Pakistan
}

*Corresponding Author: Shariat Ullah, Department of Botany, University of Malakand, Chakdara, Pakistan

\begin{abstract}
Abs tract: In the current study sixty one (61) plants were documented belonging to thirty eight (38) families used for curing twelve (12) different categories of human related ailments. There was countless agreement among the informers concerning medicinal uses of plants with Informants Consensus Factor (ICF) value ranging from 0.816 to 0.983 , with an average value of 0.942 . The study revealed that most of the informants agreed with application of Cannabis sativa to cure common pain (ICF 0.983) that showed the highest fidelity level (100\%). The result also depicted that Cannabis sativa might be cast offfor the improvement ofnew, cheap, effective, and eco-friendly herbal formulations for healthcare management.
\end{abstract}

Keywords: Evaluation; Medicinal uses; Consensus factor; Shamozai Valley; Swat; Pakistan

Abbreviations: ICF = Informants consensus factor, GIT= Gastro intestinal tract diseases and FL= Fidelity Level.

\section{INTRODUCTION}

Plant-based remedies enjoy a reputable position today, particularly in the developing countries, where basic health facility is inadequate. Native medications which are more effective, safe and cheap are gaining fame among both rural and urban areas. Information from native traditional medicine or ethnic groups has played a crucial role in the finding of novel products from plants as chemotherapeutic agents [1]. The world health organization (WHO) has highlighted the importance of the traditional indigenous medicines, since a large majority of rural people in the developing countries still rely these medicines as the first protection in health care [2]. Pakistan is rich with a distinctive biodiversity, consisting of nine major ecological zones. Due to its pleasant climate, Pakistan is rich in medicinal floras which are distributed over a large area. Pakistan has about 6,000 species of natural plants of them about 400-600 are considered to be therapeutically important. In Pakistan, medicinal plants are mainly used by hakims. Unfortunately, very little devotion has been given to the ethno botanical feature of plants as hakims are only concerned with the floral and vegetative parts of medicinal plants without any concerned to their botanical characteristics, or distribution in the various ecological territories of Pakistan [3].

Plants have been cast-off since the beginning of human civilization for readymade food, medicines for numerous diseases, fodder/ forage for cattle, burning, flower for celebration, services to earn, honey collection, making agricultural tools, timber for construction and many other useful items [4]. Above 5000 plant species belonging to angiosperms are castoff worldwide for medicinal purposes. Medicinal plant products have been used successfully for various illnesses both externally and internally. Despite the increasing use of synthetic drugs, plants materials have persisted as the "treatment of choice" as they have no or fewer side effects [5]. Modern pharmacopeia still contains at least 25\% drugs derived from plants [6] the sub -tropical areas of Pakistan are a diverse habitat for variation plant ,these areas lie in the Hindu Kush and lesser Himalayas [7]. The natural resources of Hindu Kush - Himalayas are deteriorating more rapidly than many other regions around the world.

The study of local uses of plants in Pakistan has been increasing at alarming rate during the last few years and has assisted the collection of an important knowledge. In Khyber Pakhtunkhwa (KP) of Pakistan [8]; [9]; [10]; [11]; [12]; [13]; [14]; [15]; [16]; [17] have compiled medicinal plants from various territories, but to our information no proper ethnobotanical study of medicinal plants used 
Evaluation of Informant Consensus Factor of Medicinal Plants Used in Shamozai Valley SWAT, KPK, Pakistan

locally for various ailiment in Shamozai valley, Swat, (KP) of Pakistan has been made. The objective of the current study was to enlist and compile the vast indigenous knowledge.

\section{Materials ANd Methods}

\subsection{Study Area}

The current study was carried out in Shamozai valley adjoining border of districts Dir Lower and Swat, Khber Pakhtunkhwa, Northern Pakistan. It lies in Hindu Kush range at $34^{\circ} 41^{\prime}$ 03. 09" N latitude and $72^{\circ} 07$ ' 35.82" E longitude. It is situated at a distance of $35 \mathrm{~km}$ away from Chakdara on the main Dir Swat road. The climate is cold in winter and warm in summer. The valley is populated with medicinal plants and the indigenous people mostly used them as a medication for various diseases. This remote area was selected to document the old traditional knowledge because in past there was a lack of medical facilities and mostly the people belongs to a poor families and can,t effort modern medication only Hakims and Pansaries uses different medicinal plants for curing different diseases.

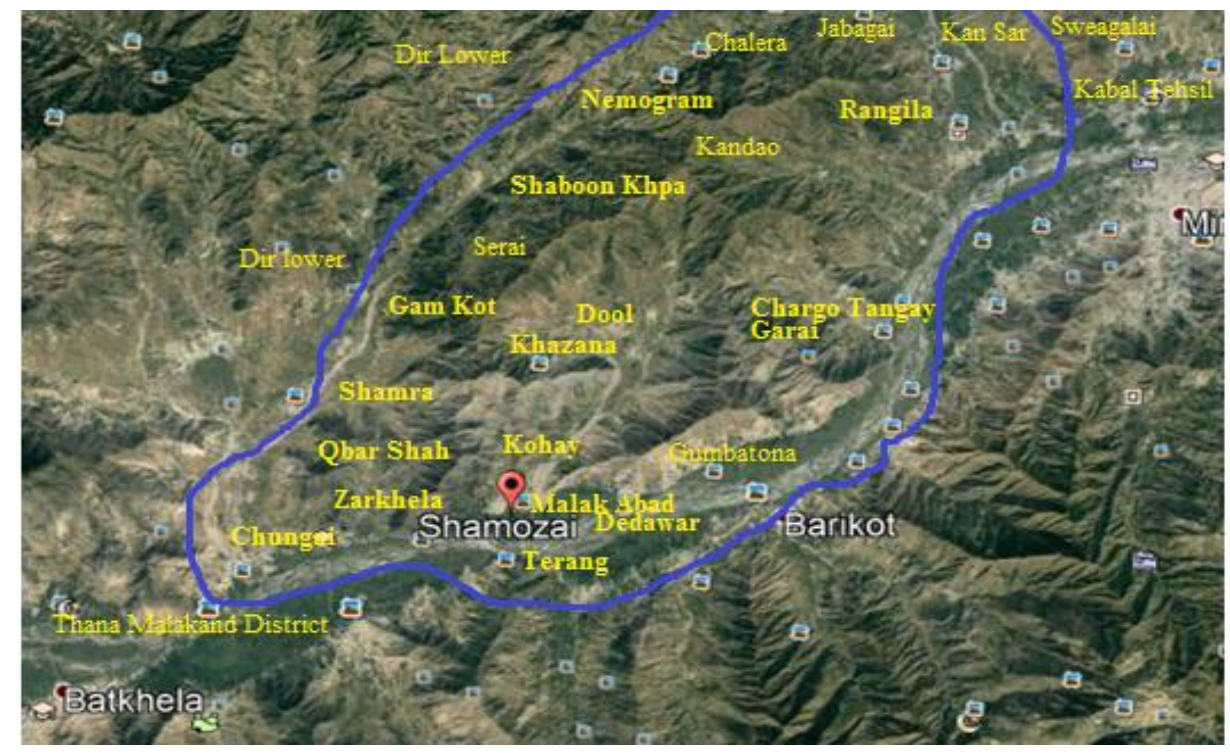

Fig1. Map of the study area

\subsection{Compilation of Data}

The study area was thoroughly visited four times in different seasons of the year 2017. Voucher specimens for each species have been collected and processed using standard herbarium techniques [18]. The specimens were identified consulting different floras, viz: [19]. Voucher specimens were deposited at Herbarium University of Malakand. Ethno medicinal information's have been collected through Participatory Rural Appraisal (PRA), which is based on interaction with indigenous people and direct observation in the field [20]. The information's have been collected through semi-structured interviews with local inhabitants involved in the plants management [18]. A total of 200 residents have been interviewed during the field survey, information on uses of plants to cure different diseases of human being, parts used, have been collected. Based on the information's obtained from the informants and all the reported diseases have been classified into 12 categories.

The level of similarity among information delivered by various informants was calculated by using Informants' Consensus Factor, ICF [21] by using the following formula:

$$
\mathrm{ICF}=\mathrm{Nur}-\mathrm{Nt} /(\mathrm{Nur}-1)
$$

Where, Nur $=$ number of use reports from informants for a specific plant-use category; NT $=$ number of taxa or species that are used for that plant use category for all informants.

ICF values range between 0 and 1 , where ' 1 ' indicates the highest level of informant agreement. The fidelity level (FL), the percentage of informants claiming the use of a certain plant species for the same major purpose, was calculated for the most frequently reported diseases or ailments as: FL $(\%)=(\mathrm{Np}$ $/ \mathrm{N}) \times 100$ Where, $\mathrm{Np}=$ number of informants that claim a use of a plant species to treat a particular disease; $\mathrm{N}=$ number of informants that use the plants as a medicine to treat any given disease [18]. 


\section{RESULTS AND DISCUSSION}

A total 61 plants belonging to 38 families have been listed for curing of 12 categories of ailments. Out of 52 formularies, 45 were of oral application and 7 of external applications. Among the noted taxa, herbs were characterized by (34) species followed by trees (19) and shrub (8) species. For each species botanical name, family, local name, ailments to be treated, and part(s) used were recorded (Table1). Use of plant parts as medicine among the informants demonstrates variations. Leaves were most commonly used part, followed by fruits, stem, whole plant, seed, bulb, bark, root, spike, latex, resin and gums (Table 1). Similar trend of harvesting leaves for medicinal use has also been reported from Lawachara National Park (Uddin et al., 2012). In the study area hazard to the species was marginal as leaves were the leading plant part used for medicinal purposes. It was detected that the collection of part of plant as medicinal part from the wild were not supportable. According to residents, this type of activity is done by the collectors related to illegal trade of medicinal plants. Cannabis sativa $\mathrm{L}$ is susceptible to this type of activity in the area.

ICF values were calculated to know the agreement among the informants for consumption of plants to treat certain disorder categories. The ICF values were presented in (Table 2). It was found that the ICF values vary from 0.816 to 0.983 with an average value of 0.942 . Common cold \& fever has the highest ICF value 0.983 with 188 use-reports for (4) species. The species accountable for high consensus was Cannabis sativa with 188 of 200 described events, linked by ineffectiveness cardiovascular diseases (ICF $=0.969 ; 100$ use-reports, 3 species), hepatitis (ICF $=0.974 ; 40$ use-reports, 2 species) and antihelminthic (ICF= 0.974, 120 use reports, 4 species). Medicinal plants thought to be effective in treating specific disorder having high ICF values. The high ICF value for common cold $\&$ fever clearly indicated that this ailment is common in the area. High ICF values also showed that the species conventionally used to treat these ailments were worth searched for bioactive compounds. The least agreement ( $\mathrm{ICF}=0.875$ and $\mathrm{ICF}=0.816$ ) between the informants was observed for plants used to cure eye, ear, nose, mouth diseases and GIT diseases respectively. The low ICF value recorded in the area would be due to a lack of communication among people in different areas (Table 2).

Table1.Documentation of medicinal plants with scientific name, local name, parts used, and ailments

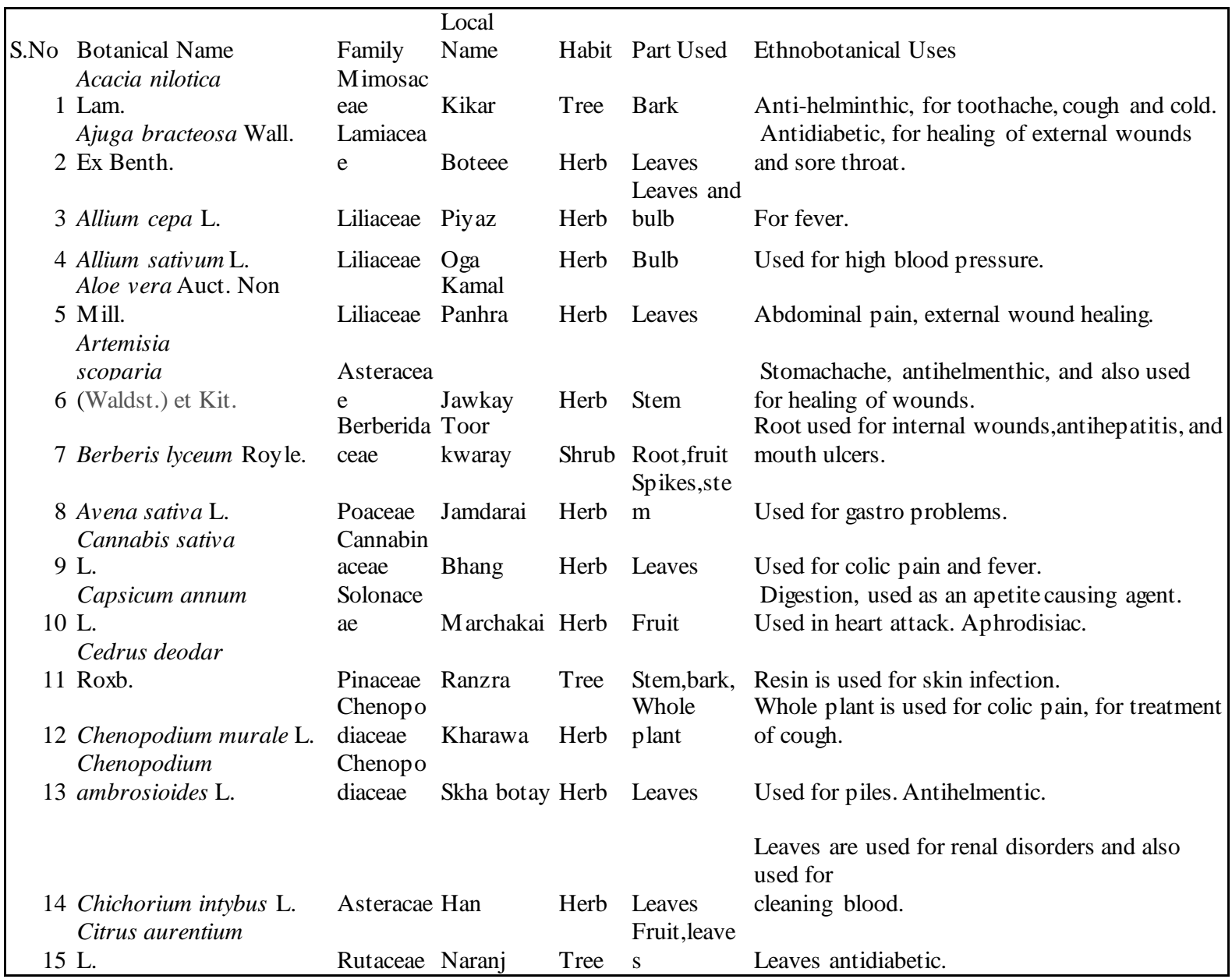




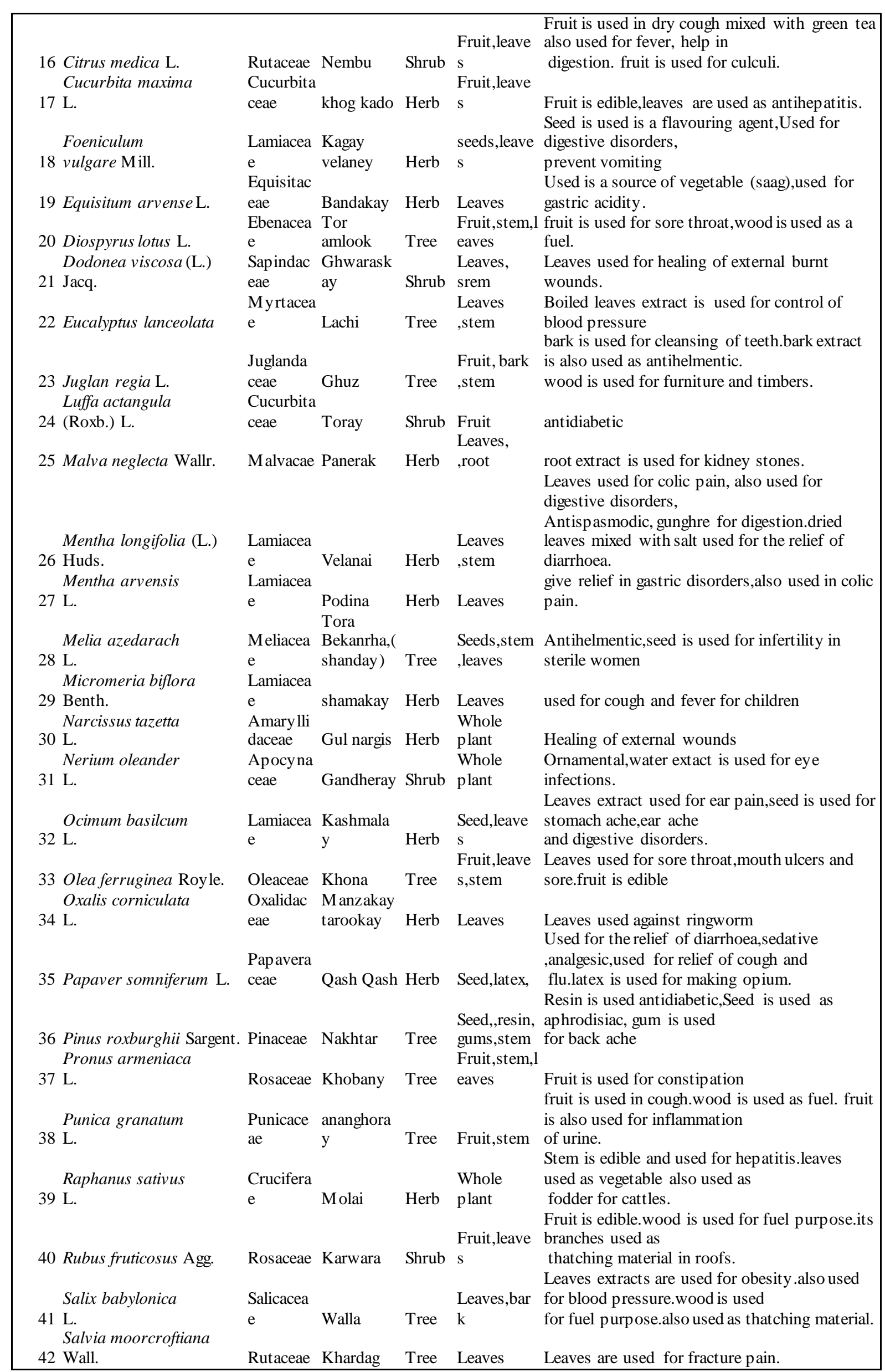


Evaluation of Informant Consensus Factor of Medicinal Plants Used in Shamozai Valley SWAT, KPK, Pakistan

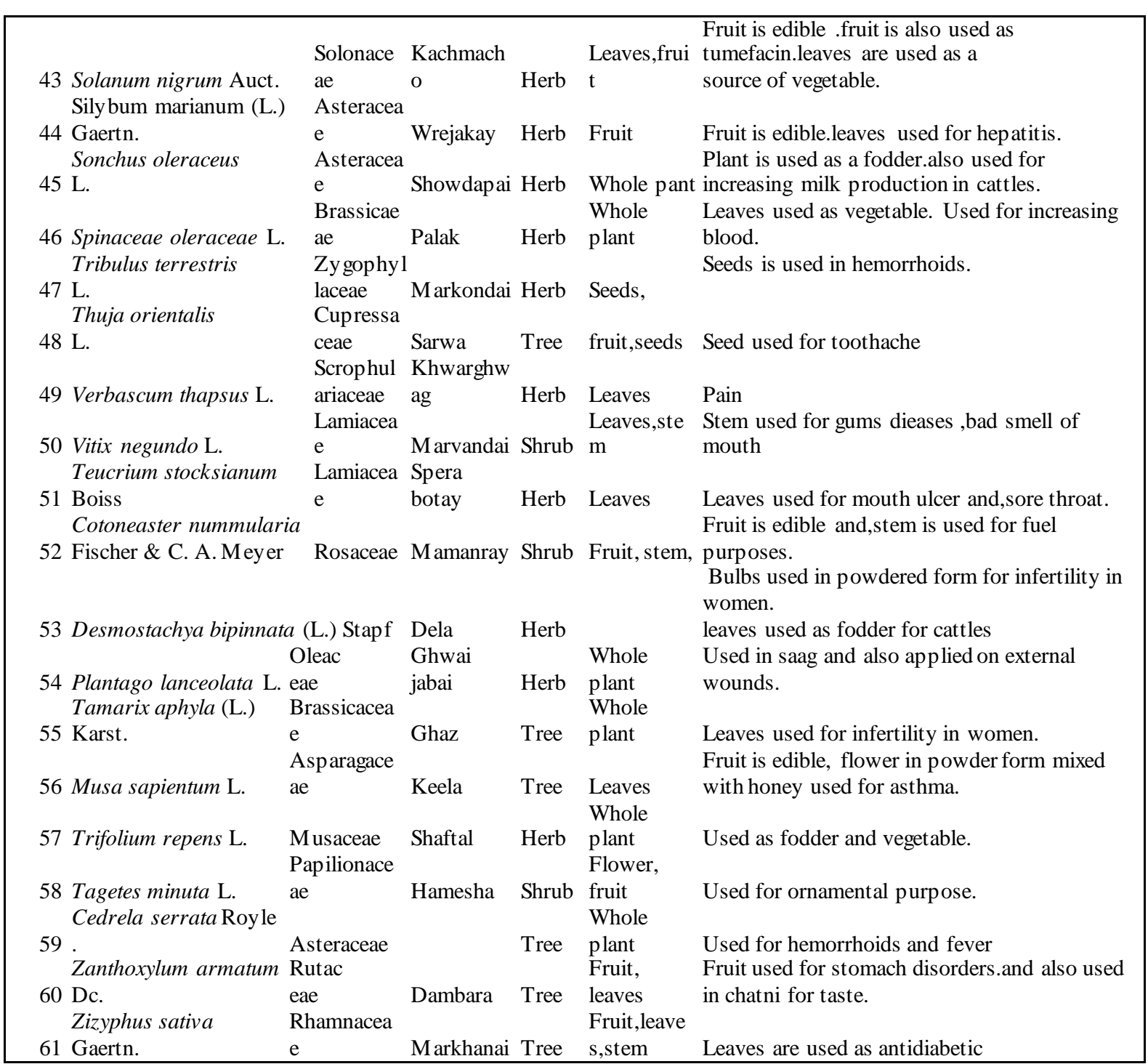

To find traditionally significant medicinal species in the society, Fidelity Level (FL) of plants has been predicted based on use reports which have been cited by 50 or more informants being used for a given illness. The FL values are shown in (Table 3). The investigation showed that the highest FL value was recorded for Cannabis sativa followed by Aloe vera, Ajug a bracteosa, Artemisia scoparia, Capsicum annum and Narcissus tazetta. The least FL values were found for Chichorium intybus and Foeniculum vulgare. FIC and FL result revealed that most commonly used species in the area is Cannabis sativa $(\mathrm{ICF}=0.983)$ with 188 use-reports and FL value $(94 \%)$. When choosing the most ideal species for each ailment category, we took the high Fidelity Level (\%) in each category of ailment.

Table2. Categories of disorders and informant consensus factor (ICF) for each grouping

\begin{tabular}{|l|l|l|l|}
\hline Diseases Category & Use report (Nur) & Taxa $(\mathrm{Nt})$ & *ICF \\
\hline Common cold \& fever & 188 & 4 & 0.983 \\
\hline Cardiovascular diseases & 100 & 3 & 0.979 \\
\hline Hepatitis & 40 & 2 & 0.974 \\
\hline Anti- helminthic & 120 & 4 & 0.974 \\
\hline Common Pain & 166 & 6 & 0.969 \\
\hline Renal+ Urinary disorder & 60 & 3 & 0.966 \\
\hline Diabetics & 150 & 7 & 0.959 \\
\hline Wound & 90 & 6 & 0.943 \\
\hline Sexual diseases & 35 & 3 & 0.941 \\
\hline Respiratory Diseases & 25 & 3 & 0.916 \\
\hline Eye, Ear, Nose, Mouth diseases & 25 & 4 & 0.875 \\
\hline GIT diseases & 50 & 10 & 0.816 \\
\hline
\end{tabular}

*ICF= Informants consensus factor, GIT= Gastro intestinal tract diseases 
Evaluation of Informant Consensus Factor of Medicinal Plants Used in Shamozai Valley SWAT, KPK, Pakistan

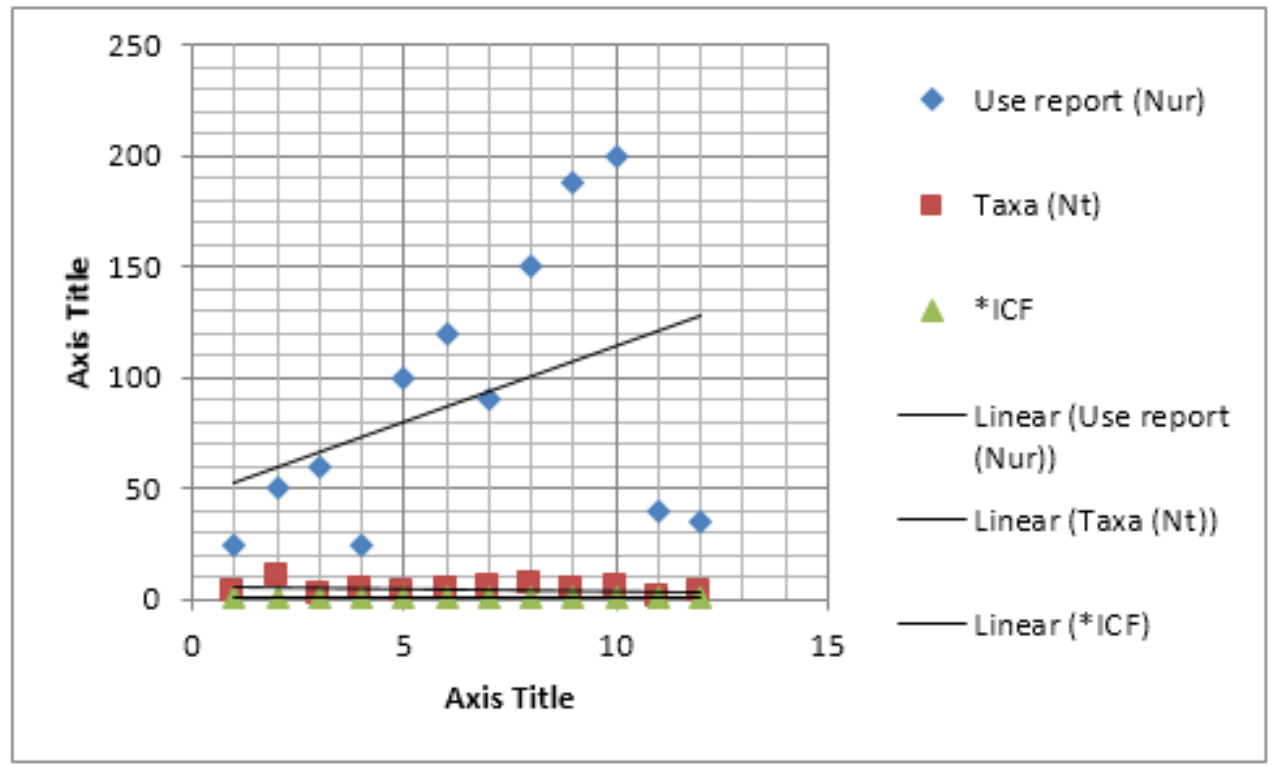

Fig2. Categories of disorders and informant consensus factor (ICF) for each grouping

Table3. Utmost frequently used plants for various illness groups based on highest FL (\%) in each disease category ( Total informants $=200)$.

\begin{tabular}{|l|l|l|l|}
\hline Scientific Name & Disease Category & Use Report & Fidelity Level (\% \\
\hline Cannabis sativa L. & Common cold \& fever & 188 & 94 \\
\hline Aloe vera Auct. Non Mill. & Common Pain & 166 & 83 \\
\hline Ajuga bracteosa Wall. Ex Benth. & Diabetics & 150 & 75 \\
\hline Artemisia scoparia & Anti- helminthic & 120 & 60 \\
\hline Capsicum annum L. & Cardiovascular diseases & 100 & 50 \\
\hline Narcissus tazetta L. & Wound & 90 & 45 \\
\hline Chichorium intybus L. & Renal+ Urinary disorder & 60 & 30 \\
\hline Foeniculum vulgare Mill. & GIT diseases & 50 & 25 \\
\hline
\end{tabular}

\section{CONCLUSION}

The present work is the first attempt to document the ethno medicinal information on plants in the valley which offer better choice for the selection of broadly used medicinal plants looking for bioactive compounds to cure illnesses.

\section{ACKNOWLEDGMENTS}

I am thankful to all the informants of the area for sharing their knowledge and cooperation during filed study.

\section{REFERENCES}

[1] Katewa SS, Chaudhary BL, Jain Z. 2004. Folk herbal medicines from tribal area of Rajasthan, India. J Ethnopharma, 92: 41-46.

[2] Goleniowski ME, Bongiovanni GA, Bongiovanni L, Palacio CO, Cantero JJ. 2006. Medicinal plants from the "Sierra de Comechingones", Argentina. J Ethnophama, 107: 324-341.

[3] Hamayun M, Khan MA, Hayat T. 2005. Ethnobotanical profile of Utror and Gabral valleys, district Swat, Pakistan. Ethnobotany leaflets

[4] Ahmad S, Ali A, Beg H, Dasti AA, Shinwari ZK. 2006. Ethnobotanical studies on some medicinal plants of Booni valley, district Chitral Pakistan. Pak J Weed Sci Res, 12: 183-190.

[5] Ibrar M, Hussain F, Sultan A. 2007. Ethnobotanical studies on plant resources of Ranyal hills, district Shangla, Pakistan. Pak J Bot, 39: 329-337.I

[6] Shinwari ZK, Rehman M, Watanabe T, Yoshikawa Y. 2006. Medicinal and Aromatic Plants of Pakistan (A Pictorial Guide). Kohat University of Science and Technology, Kohat, Pakistan. pp. 492.

[7] Khan SM, Page S, Ahmad H, Harper D. 2014. Ethno-ecological importance of plant biodiversity in mountain ecosystems with special emphas is on indicator species of a Himalayan Valley in the northern Pakistan. Ecological Indicators, 37: 175-185. 
[8] Haq I, Hussain M.1993. Medicinal plants of Mansehra. Hamdard Medicus, 36(3): 63-100.

[9] Badshah L, Hussain F, Mohammad Z. 1996. Floristic and Ethnoecological studies on some plants of Pirghar Hills, S. Wazirstan, Pakistan. Pakistan. Pak J Plant Sci, 2 (2): 167-177.

[10] Inam B, Sultana K, Qureshi RA, Malik S. 2000. A checklist of plants of Bhogarmang, Siran valley, N.W.F.P., Pakistan. Hamdard Medicus, 43(4): 62-75.

[11] Hussain M. 2003. Palynological and Ethnobotanical Studies of Chrysanthemum leucanthemum from Gallies (Abbottabad), Pakistan. Hamdard Medicus, XLVI (3): 13-14.

[12] Dastagir G, Abbasi AM. 2004. Folk medicines used for the treatment of jaundice in district Haripur, Pakistan. Pak J Plant Sci, 10 (2): 119-123.

[13] Abbasi AM, Dastagir G, Hussain F, Sanaullah P. 2005. Ethnobotany and marketing of crude drug plants in district Haripur, Pakistan. Pak J Plant Sci, 11(2): 103-114.

[14] Hussain M, Shah GM, Khan MA. 2006. Traditional medicinal and economic uses of Gymnosperms of Kaghan valley, Pakistan. Ethnobotany leaflets.

[15] Hussain K, Shahzad A, Hussnain SZ. 2008. An Ethnobotanical survey of important wild Medicinal plants of Hattar District Haripur, Pakistan. Ethnobotany Leaflets, 12: 29-35.

[16] Abbasi AM, Khan MA, Ahmad M, Zafar M, Khan H, Muhammad N, Sultana S. 2009. Medicinal plants used for the treatment of Jaundice and Hepatitis based on Socio-Economics documentation. Afr J Biotechnol, 8 (8): 1643-1650.

[17] Ali H, Qaiser M. 2009. The Ethnobotany of Chitral Valley, Pakistan with Particular Reference to Medicinal Plants. Pak J Bot, 41(4): 2009-2041.

[18] Alexiades MN.1996. Selected guidelines for ethnobotanical research: A Field Manual. The New York Botanical Garden, New York, pp. 99-133.

[19] Hooker JD. 1872-1897. Flora of British India, Vols. 1-7. Bishen Singh Mahendra Pal Singh, Dehra Dun, India.

[20] Martin GJ. 1995. Ethnobotany: A Methods Manual. Chapman \& Hall, London.

[21] Trotter RT, Logan MH. 1986. Informant census: A new approach for identifying potentially effective medicinal plants. In: Etkin, L.N. (Ed.), Plants in indigenous medicine and diet. Redgrave, Bedford Hill, New York, pp. 91-112.

[22] Uddin MZ, Hassan MA, Rahman MM, Arefin MK. 2012. Ethno-medico-botanical study in Lawachara National Park, Bangladesh. Bangladesh J Bot, 41 (1): 97-104.

Citation: S. Ullah et al., "Evaluation of Informant Consensus Factor of Medicinal Plants Used in Shamozai Valley SWAT, KPK, Pakistan", International Journal of Medicinal Plants and Natural Products (IJMPNP), vol. 4, no. 2, pp. 1-7, 2018. http://dx.doi.org/10.20431/2454-7999.0402001

Copyright: () 2018 Authors. This is an open-access article distributed under the terms of the Creative Commons Attribution License, which permits unrestricted use, distribution, and reproduction in any medium, provided the original author and source are credited. 